\title{
Spiritual Nursing Education, Spiritual Well-Being and Mental Health in Nursing Students
}

\author{
Jeong In Lee ${ }^{1}$ and Mi Lim $\operatorname{Im}^{2^{*}}$ \\ 'Department of Nursing Science, Daejeon Institute of Science and Technology, Daejeon, Korea; jilee@dst.ac.kr \\ 2Department of Nursing Science, Baekseok University, Cheonan, Korea; nug21c@bu.ac.kr
}

\begin{abstract}
Objectives: To examine spiritual nursing education, spiritual well-being and mental health of college students majoring in nursing and determine the association between spiritual nursing education, spiritual health and mental health. Methods/ Statistical Analysis: 194 nursing majors at a college were selected, regardless of grade, by convenience sampling. The sample size was estimated to be 110 or more by a G power 3.1 programs at the significance level of .05 , with the effect size of . 3 and testability of .95. Of 250 questionnaires returned, a total of 194 copies were analyzed, with the exception of those containing incomplete responses. Findings: As for spiritual well-being by the general characteristics, the students with a religion scored higher in spiritual well-being than those with no religion $(t=8.940, \rho=.000)$ and the students considering themselves to be healthy scored higher in spiritual well-being than those considering their health status to be at the average level, showing statistically significant differences $(F=4.599, \rho=.033)$. Female students scored higher in mental health than male ones, showing significant differences $(t=-2.078, \rho=.039)$. The students with a religion scored higher in mental health than those with no religion, showing significant differences $(t=2.239, \rho=.026)$. The students considering themselves to be healthy scored lower in mental health than those considering their health status to be at the average level or lower, showing significant differences $(F=25.436, \rho=.000)$. The students satisfied with family life scored lower in mental health than those dissatisfied it $(t=-2.681, \rho=.008)$ and the students satisfied with campus life scored lower in mental health than those dissatisfied it $(t=-2.082, \rho=.039)$. There was statistically insignificant correlation between spiritual well-being and mental health of the respondents. Improvements/Applications: It is required to study spiritual well-being tools for the sub-areas of the areas of life satisfaction/self-realization, faith/belief and life/responsibility.
\end{abstract}

Keywords: Mental Health, Spiritual Nursing Education, Spiritual Well-Being

\section{Introduction}

Nursing students are in special conditions, unlike those majoring in other fields. They also live campus lives, while performing clinical practices. This exposes them to continuous stress. Such stress has influenced emotional state as well as study and daily life. The emotional and spiritual health is indispensable for future health professionals. Also, it has recently become an important issue to get access to patients in a spiritual way. Therefore, spiritual nursing education is crucial for nursing students who have to meet patients in need of spiritual nursing. However, it is a challenge to educators to teach nursing students spiritual nursing. Indeed, spiritual nursing is considered to belong to the nursing field, but there is no consensus on the definition of spiritual nursing, nor is any common training coursework presented in nursing education curricula.

In South Korea, spiritual nursing education is offered by a small number of Christian universities. $\operatorname{In}^{1}$ argued that nursing education should lead nursing students to seek spiritual basis in the history of nursing professionals and that it helps students develop analytical and critical abilities to introduce a wide range of definitions on spirituality and religion. $\mathrm{In}^{2}$ contented self-recognition development is an element of spiritual nursing, recommending case study and reflection travel as methods to promote self-recognition and humbleness necessary

*Author for correspondence 
for spiritual nursing. According to ${ }^{\frac{3}{2}}$, a nursing process approach predominated and an intervention of using self as a therapeutic tool and supporting religion and spiritual practice was presented in the major nursing teaching materials used for undergraduate nursing education in the US and Canada. Pointing out the definition of spiritual nursing is ambiguous ${ }^{3}$, however, maintained that attention should be paid to religiosity and spirituality and that spiritual nursing requires a broad and comprehensive function of cognition. In the future, it is necessary to develop a spiritual nursing curriculum, since there is a lack of specific skill to motivate nurses to take interest in and support the spiritual requirements of patients and it is not clear what kind of education should be offered to undergraduate students to what extent. According to ${ }^{4}$, spiritual education was offered 1 to 28 hours and composed of self, transcendental being, connectivity to nature, self-recognition, spirituality, spiritual nursing area, definition of spirituality and spiritual nursing, spiritual agony, stress and Thatcher theory, meaning, purpose and transcendentality in sickness, spiritual assessment, hope, Thatcher strategy, nursing process, hindrance factors for spiritual nursing etc. In South Korea, three of 14 Christian universities which gives courses on nursing and mission training, spiritual nursing, spiritual nursing in practice, Christian values and spiritual health, etc. Spiritual well-being is an ability to develop human spiritual nature to the maximum and a well-being status to maintain right relationships with God, self, neighbors and nature and to reach integration, order, harmony and peace. $\operatorname{In}^{\frac{5}{5}}$ asserted that spiritual health is to have an ability for humans to be comfortable by establishing right relations with God, to set a basic purpose in life, to learn how to enjoy and accomplish love, joy and peace and to help accomplish potentials to the maximum. Spiritual well-being is characterized by inner peace, compassion for others, respect of life, thankfulness and agreement and diversity. Spiritual well-being is an activist expression showing spiritual health most clearly and emerges as inner peace, hope, compassion for others, respect of life, thankfulness and satisfaction, supportive relationships with others, ethical behaviors, positive self-concept, etc. In other words, spiritual well-being is identical with life principle that has an influence on human existence and is characterized in that human inner resources are healthy on the whole and complete the best values of life, such as hope, meaning and love. There is a religious spiritual well-being in relationships with God and an existentialist spiritual well-being in the meaning and purpose of life. Mental health is a physically and mentally healthy status in which individuals can grasp realities with reason to adapt to physical, social and psychological environments and is a concept including abilities to form and maintain healthy human relationships, to endure tension in daily life without resisting or avoiding society and to grow and develop self ${ }^{6}$. Part of whole health, spiritual well-being should be in correlation with health, but there are a very small number of studies practically demonstrated. $\mathrm{In}^{\mathrm{T}}$ claimed that there are significant correlations between mental health and intrinsic values, saying that spiritual well-being is an essential system to lay groundworks for an individual's behaviors. In particular, there were positive correlations between lack of spirituality and feeble mental health: Depressed subjects were preoccupied with meaninglessness, emptiness, alienation, ego-centeredness and narcissism. $\operatorname{In}^{8}$ suggested that spiritual well-being acted as a psychological protective element for adolescents in dangerous environment and that existential spiritual well-being is associated with the mental health of adolescents ${ }^{9}$. According to ${ }^{\frac{10}{}}$, spiritual elements are related with depression and should be included in the treatment of depression. There were negative correlations between spiritual well-being and depression in university students and adults $\frac{11,12}{}$. Many domestic and foreign studies indicate that there are close relationships between spiritual well-being and mental health $\frac{13}{}$. The studies include the concept and recognition of spiritual nursing, the relationships between spiritual well-being and spiritual nursing, spiritual nursing education and death attitude, spiritual well-being, hope and health and self-esteem and spiritual well-being, spiritual well-being, stress and depression, spiritual well-being and life satisfaction and spiritual well-being, self-efficacy and career attitude, spiritual well-being and spiritual care importance, spiritual empathy expression and spiritual nursing recognition, spirituality and spiritual care model in nursing practice and spiritual care tools. Seeing that Christian universities rarely offer nursing education based on Christian values, it is meaningful that the present study attempts to look into the relationships between spiritual nursing education in practice and spiritual well-being and mental health, as a model of spiritual nursing education at Christian universities. This study was designed to enhance its efficacy as a basic data for spiritual nursing practice and to offer patients effective spiritual nursing based on Christian values. 


\section{Proposed Work}

194 nursing majors at a college were selected, regardless of grade, by convenience sampling. The sample size was estimated to be 110 or more by a $G$ power 3.1 programs at the significance level of .05, with the effect size of .3 and testability of .95 . Of 250 questionnaires returned, a total of 194 copies were analyzed, with the exception of those containing incomplete responses.

The following instruments were used in this study:

The spiritual well-being scale was adaptation of the scale developed by; it was a five-point scale with twenty items and the scores ranged from 5.3 to 2.35 , with higher scores being more spiritually well. Its reliability was Cronbach's $\alpha=.93$ in and .859 in this study.

The mental health scale was the Symptom Checklist90-Revision (SCL-90-R), which was developed by, revised by Derogatis and his colleagues, standardized by to meet the South Korean conditions and reduced to a five-point scale with 47 items by $\frac{13}{3}$ through factor analysis. The scores ranged from 3.85 to 1.00 , with higher scores being unhealthier. Its reliability was Cronbach's $\alpha=.946$ in Kim and .970 in this study.

Spiritual nursing education refers to the course titled The Christian World View and Spiritual Health freshmen attend in a college. This two-credit course is provided in two-hour weekly sessions in the first term for freshmen and addresses the Christian world view, the understanding of spiritual health, nurses and God, the concept of spiritual nursing, spiritual needs, the fundamental concept of spiritual health, the biblical concept of human beings, fundamental attitudes as a spiritual care giver, ethics of Christian nurses, cases of spiritual nursing and so on. The instrument in this study was composed of items concerning the attendance at the course of spiritual nursing education and its need and importance.

The data were collected from March to August 2014 and the respondents were given an explanation of the goals and contents and of the possibility to withdraw from the research at any time during the process of data collection. The students who volunteered to participate in the research were asked to complete a written consent before data collection.

\section{Results and Conclusion}

This study obtained the following results:

- As for spiritual well-being by the general characteristics, the students with a religion scored higher in spiritual well-being than those with no religion $(t=8.940, \rho$ $=.000)$ and the students considering themselves to be healthy scored higher in spiritual well-being than those considering their health status to be at the average level, showing statistically significant differences $(\mathrm{F}=4.599, \rho=.033)$ as shown in Table 1.

- Female students scored higher in mental health than male ones, showing significant differences $(t=-2.078, \rho=$ .039). The students with a religion scored higher in mental health than those with no religion, showing significant differences $(t=2.239, \rho=.026)$. The students considering themselves to be healthy scored lower in mental health than those considering their health status to be at the average level or lower, showing significant differences ( $F$ $=25.436, \rho=.000$ ). The students satisfied with family life scored lower in mental health than those dissatisfied it $(\mathrm{t}$ $=-2.681, \rho=.008)$ and the students satisfied with campus life scored lower in mental health than those dissatisfied it $(\mathrm{t}=-2.082, \rho=.039)$ as shown in Table 1 .

- The students receiving spiritual nursing education scored lower in mental health than those not receiving it $(t=-2.584, \rho=.011)$. There were significant differences in spiritual well-being by the need and importance of the course: The students considering the course to be highly necessary scored higher in spiritual well-being than those considering it necessary, average, unnecessary or totally unnecessary $(F=37.395, \rho=.000)$ and the students considering it very important scored higher in spiritual well-being than those considering it important, average, unimportant or totally unimportant $(\mathrm{F}=41.350, \rho=.000)$ as shown in Table 2 .

- There was statistically insignificant correlation between spiritual well-being and mental health of the respondents as shown in Tables 3 and 4.

According to spiritual health varied according to gender, marital status, religion and health. The present study showed that there were significant differences in spiritual health according to religion or health, while there was no significant difference in spiritual health according to gender or marital status. Subjects with religion had better spiritual well-being than those without religion $(\mathrm{t}$ $=8.940, \mathrm{p}=.000)$. Likewise, subjects with good health received higher scores in spiritual well-being than those with average health $(F=4.599, \rho=.033)$. Higher scores mean better status in spiritual well-being. According to ${ }^{\frac{14}{4}}$, spiritual well-being, marital status and religion turned out to be significant variables: There were significant differences between spiritual well-being and religion. 
Table 1. Differences of spiritual wellness and mental health by general characteristics of subjects $\mathrm{N}=194$

\begin{tabular}{|c|c|c|c|c|c|c|c|c|}
\hline \multirow[t]{2}{*}{ Characteristics } & \multirow[t]{2}{*}{ Categories } & \multirow[t]{2}{*}{ N (\%) } & $\begin{array}{l}\text { spiritual } \\
\text { wellness }\end{array}$ & $t$ or $F$ & \multirow[t]{2}{*}{ Scheffe } & $\begin{array}{l}\text { mental } \\
\text { health }\end{array}$ & t or $F$ & \multirow[t]{2}{*}{ Scheffe } \\
\hline & & & $\mathrm{M} \pm \mathrm{SD}$ & (p) & & $\mathrm{M} \pm \mathrm{SD}$ & (p) & \\
\hline Sex & $\begin{array}{c}\text { Male } \\
\text { Female }\end{array}$ & $\begin{array}{c}21(10.8) \\
173(89.2)\end{array}$ & $\begin{array}{l}3.54 \pm 0.52 \\
3.46 \pm 0.63\end{array}$ & $\begin{array}{l}.498 \\
(.619)\end{array}$ & 1. & $\begin{array}{l}1.64 \pm 0.53 \\
1.94 \pm 0.64\end{array}$ & $\begin{array}{l}-2.078 \\
(.039) *\end{array}$ & 2. \\
\hline Religion & $\begin{array}{l}\text { Yes } \\
\text { No }\end{array}$ & $\begin{array}{l}114(58.8) \\
80(41.2)\end{array}$ & $\begin{array}{l}3.75 \pm 0.61 \\
3.07 \pm 0.35\end{array}$ & $\begin{array}{l}8.940 \\
(.000)^{*} \\
\end{array}$ & 3. & $\begin{array}{l}1.99 \pm 0.70 \\
1.79 \pm 0.51 \\
\end{array}$ & $\begin{array}{l}2.239 \\
(.026) * \\
\end{array}$ & 4. \\
\hline Health status & $\begin{array}{c}\text { Healthy(a) } \\
\text { Moderate(b) } \\
\text { No healthy(c) }\end{array}$ & $\begin{array}{l}106(54.6) \\
68(35.1) \\
20(10.3) \\
\end{array}$ & $\begin{array}{l}3.58 \pm 0.63 \\
3.32 \pm 0.57 \\
3.44 \pm 0.60 \\
\end{array}$ & $\begin{array}{l}4.599 \\
(.033)^{*}\end{array}$ & $a>b$ & $\begin{array}{l}1.73 \pm 0.54 \\
2.05 \pm 0.62 \\
2.38 \pm 0.80 \\
\end{array}$ & $\begin{array}{l}25.436 \\
(.000) *\end{array}$ & $a>b, c$ \\
\hline With Parents & \begin{tabular}{|c|} 
live together \\
Divorce/separation
\end{tabular} & $\begin{array}{c}165(85.1) \\
15(14.9)\end{array}$ & $\begin{array}{l}3.50 \pm 0.63 \\
3.40 \pm 0.55\end{array}$ & $\begin{array}{l}.5501 \\
(.583)\end{array}$ & 5. & $\begin{array}{l}1.91 \pm 0.63 \\
1.89 \pm 0.56\end{array}$ & $\begin{array}{c}.138 \\
(.890)\end{array}$ & 6. \\
\hline Economic status & $\begin{array}{c}\text { Satisfaction } \\
\text { Dissatisfaction }\end{array}$ & $\begin{array}{l}129(66.5) \\
65(33.5)\end{array}$ & $\begin{array}{l}3.53 \pm 0.64 \\
3.37 \pm 0.56 \\
\end{array}$ & $\begin{array}{l}.1682 \\
(.095) \\
\end{array}$ & 7. & $\begin{array}{l}1.85 \pm 0.63 \\
2.02 \pm 0.64 \\
\end{array}$ & $\begin{array}{l}-1.766 \\
(.080)\end{array}$ & 8. \\
\hline Family life & $\begin{array}{c}\text { Satisfaction } \\
\text { Dissatisfaction }\end{array}$ & $\begin{array}{c}178(91.8) \\
16(8.2)\end{array}$ & $\begin{array}{l}3.49 \pm 0.63 \\
3.31 \pm 0.47\end{array}$ & $\begin{array}{l}1.123 \\
(.263) \\
\end{array}$ & 9. & $\begin{array}{l}1.87 \pm 0.62 \\
2.31 \pm 0.66\end{array}$ & $\begin{array}{l}-2.681 \\
(.008) * \\
\end{array}$ & 10. \\
\hline School life & $\begin{array}{c}\text { Satisfaction } \\
\text { Dissatisfaction }\end{array}$ & $\begin{array}{l}161(83.0) \\
30(15.5)\end{array}$ & $\begin{array}{l}3.51 \pm 0.60 \\
3.30 \pm 0.72\end{array}$ & $\begin{array}{l}1.734 \\
(.086)\end{array}$ & 11. & $\begin{array}{l}1.87 \pm 0.64 \\
2.12 \pm 0.53\end{array}$ & $\begin{array}{l}-2.082 \\
(.039) *\end{array}$ & 12. \\
\hline
\end{tabular}

Table 2. Differences of spiritual wellness and mental health by subject of Christian view and spiritual health

\begin{tabular}{|c|c|c|c|c|c|c|c|c|}
\hline \multirow[t]{2}{*}{ Characteristics } & \multirow[t]{2}{*}{ Categories } & \multirow[t]{2}{*}{ N (\%) } & $\begin{array}{l}\text { spiritual } \\
\text { wellness }\end{array}$ & t or F & \multirow[t]{2}{*}{ Scheffe } & $\begin{array}{l}\text { mental } \\
\text { health }\end{array}$ & tor F & \multirow[t]{2}{*}{ Scheffe } \\
\hline & & & $\mathrm{M} \pm \mathrm{SD}$ & (p) & & $\mathrm{M} \pm \mathrm{SD}$ & (p) & \\
\hline \multirow{2}{*}{ Taking lectures } & Yes & $137(70.6)$ & $3.49 \pm 0.64$ & .449 & \multirow{2}{*}{13.} & $1.84 \pm 0.60$ & -2.584 & \multirow{2}{*}{14.} \\
\hline & No & $57(29.4)$ & $3.44 \pm 0.57$ & $(.654)$ & & $2.10 \pm 0.67$ & $(.011) *$ & \\
\hline \multirow{5}{*}{ Necessity } & very needed (a) & $22(11.3)$ & $4.06 \pm 0.58$ & \multirow{5}{*}{$\begin{array}{l}37.395 \\
(.000)^{*}\end{array}$} & \multirow{5}{*}{$\mathrm{a}>\mathrm{b}, \mathrm{c}, \mathrm{d}, \mathrm{e}$} & $1.85 \pm 0.65$ & \multirow{5}{*}{$\begin{array}{l}1.075 \\
(.301)\end{array}$} & \multirow{5}{*}{15.} \\
\hline & needed (b) & $56(28.9)$ & $3.64 \pm 0.51$ & & & $1.90 \pm 0.62$ & & \\
\hline & moderate (c) & $79(40.7)$ & $3.33 \pm 0.58$ & & & $1.90 \pm 0.64$ & & \\
\hline & no needed (d) & $23(11.9)$ & $3.06 \pm 0.34$ & & & $1.89 \pm 0.62$ & & \\
\hline & no very needed (e) & $14(7.2)$ & $3.31 \pm 0.81$ & & & $2.14 \pm 0.66$ & & \\
\hline \multirow{5}{*}{ Importance } & very important (a) & $20(10.3)$ & $4.09 \pm 0.55$ & \multirow{5}{*}{$\begin{array}{l}41.350 \\
(.000)^{*}\end{array}$} & \multirow{5}{*}{$\mathrm{a}>\mathrm{b}, \mathrm{c}, \mathrm{d}, \mathrm{e}$} & $1.85 \pm 0.72$ & \multirow{5}{*}{$\begin{array}{c}.625 \\
(.430)\end{array}$} & \multirow{5}{*}{16.} \\
\hline & important (D) & $43(22.2)$ & $3.73 \pm 0.51$ & & & $1.96 \pm 0.65$ & & \\
\hline & moderate (c) & $97(50.0)$ & $3.35 \pm 0.55$ & & & $1.86 \pm 0.60$ & & \\
\hline & Ho important (a) & $20(10.3)$ & $2.97 \pm 0.38$ & & & $1.98 \pm 0.69$ & & \\
\hline & $\begin{array}{c}\text { no very } \\
\text { important (e) }\end{array}$ & $14(7.2)$ & $3.36 \pm 0.78$ & & & $2.10 \pm 0.66$ & & \\
\hline
\end{tabular}

Mental health significantly varied according to gen$\operatorname{der}(t=-2.078, \rho=.039)$ : Female students received higher scores than male ones. There were significant differences in mental health between subjects with and without religion $(t=2.239, \rho=.026)$ : Subjects with religion received lower scores than those without religion. This means a religion is good for mental health. Mental health significantly varied according to physical health: Subjects with good physical health received lower scores in mental health than those with average or poor physical health $(\mathrm{F}=25.436, \rho=.000)$. There were significant differences in mental health according to satisfaction with home 
Table 3. Mean scores and range for spiritual wellness and mental health $\mathrm{N}=194$

\begin{tabular}{|c|c|c|c|c|}
\hline Variables & Mean & $\begin{array}{c}\text { Standard } \\
\text { deviation }\end{array}$ & Minimum & Maximum \\
\hline $\begin{array}{c}\text { Spiritual } \\
\text { wellness }\end{array}$ & 3.47 & .618 & 2.35 & 5.32 \\
\hline $\begin{array}{c}\text { Mental } \\
\text { health }\end{array}$ & 1.91 & .633 & 1.00 & 3.85 \\
\hline
\end{tabular}

Table 4. Correlation between spiritual wellness and mental health $\mathrm{N}=194$

\begin{tabular}{|c|c|c|}
\hline \multirow{2}{*}{ Variables } & \multicolumn{2}{|c|}{$\mathbf{r}(\rho)$} \\
\cline { 2 - 3 } & Spiritual wellness & Mental health \\
\hline Spiritual wellness & - & - \\
\hline Mental health & .157 & - \\
\hline
\end{tabular}

or school life: Lower mental health scores were in subjects satisfied with home life than those dissatisfied with home life ( $t=-2.681, \rho=.008)$ and in subjects satisfied with school life than those dissatisfied with school life $(\mathrm{t}$ $=-2.082, \rho=.039)$. Lower scores mean better status in mental health.

Mental health varied according to spiritual nursing education: subjects with spiritual nursing education received lower scores in mental health than those without spiritual nursing education $(t=-2.584, \rho=.011)$. Mental health significantly varied according to the necessity or importance of class: Mental health scores were higher in subjects with high necessity than those with necessity to needlessness $(F=37.395, \rho=.000)$ and in subjects with high importance than those with importance to unimportance $(\mathrm{F}=41.350, \rho=.000)$.

According to, there were significant correlations between spiritual well-being, self-esteem and mental health. On the contrary, the present study showed that there was no significant correlation between spiritual well-being and mental health. This makes it necessary to make any further study with other target groups.

This study makes the following suggestions based on the above-mentioned results:

- It is required to study spiritual well-being tools for the sub-areas of the areas of life satisfaction/self-realization, faith/belief, and life/responsibility.

- It is demanded to study mental health tools for obsessional thinking, interpersonal sensitivity, depression, anxiety, hostility, fear unrest and paranoia.
- It is needed to measure the relationships between spiritual well-being and other variables, such as anxiety, depression, self-esteem, life quality and hope.

- It is requested to study basic data for the mental health nursing of adolescents in relationships between spiritual well-being and various variables.

- It is desired to study spiritual well-being and communication in nursing artistic terms.

\section{References}

1. Catanzaro AM, McMullen KA. Increasing nursing students' spiritual sensitivity. Nurse Educator. 2001; 26(5):221-6.

2. Bush T. Journaling and the teaching of spirituality. Nurse Education Today. 1999; 19: 20-8.

3. Pesut B. Spirituality and spiritual care in nursing fundamentals textbooks. The Journal of Nursing Education. 2008; 47(4):167-73.

4. Timmins F, Neill F. Teaching nursing students about spiritual care - A review of the literature. Nurse Education Practice. 2013; 13(6):499-505.

5. Chapman LS. Spiritual health: A component missing from health promotion. American Journal of Health Promotion. 1986; 1(1):38-41.

6. Halla K. Study on relationship between self-concept and mental health of nursing students. [Master's thesis]. Hanyang University; 2012.

7. Westgate CE. Spiritual wellness and depression. Journal of Counseling and Development. 1996; 75(1):26-35.

8. Jiah P. The relationship to resilience, spiritual well-being and parent attachment. [Master's thesis]. Ewhawomens University; 2013

9. Eun LY. The relationship of spiritual wellness and mental health in adolescents. Child Nursing Society Symposium; 2008. p. 1-12.

10. Lewis SE. A search for meaning: Making sense of depression. Journal of Mental Health. 1995; 4:469-82.

11. Brennan PF, Fehring RJ, Kellre ML. Psychological and spiritual well being in college students. Research in Nursing and Health. 1987; 10(6):1-12.

12. Hyun SK. Spiritual wellbeing, stress, depression and selfesteem in undergraduate. Journal of Korean Psychology. 2005; 17(4):1077-95.

13. Lim IM. Focus group interview for 'Christian view and spiritual nursing' curriculum organization. The Christian University and Academy. 2013; 6:306-31.

14. In-soon J. A study on spiritual well-being, depression, and health status of elderly women in a Community. Korean Journal of Women Health Nursing. 2004; 10(2):91-8. 